\title{
PENYESUAIAN POLA DASAR BUSANA SISTEM INDONESIA UNTUK WANITA INDONESIA DENGAN BENTUK BADAN GEMUK
}

\author{
Nurul Hidayah ${ }^{1^{*}}$, Yasnidawati $^{2^{*}}$ \\ Program Studi Pendidikan Kesejahteraan Keluarga Jurusan Ilmu Kesejahteraan Keluarga \\ Fakultas Pariwisata dan Perhotelan \\ Universitas Negeri Padang \\ Jl. Prof. Dr. Hamta, Air Tawar Padang, Kel. Air Tawar Barat, Kec. Padang Utara, Kota Padang, Kode Pos 25171 \\ Sumatera Barat. Indonesia \\ Email:nurulwidayatiehidayah93@gmail.com
}

\begin{abstract}
Abstrak
Pembuatan pola busana merupakan salah satu proses terpenting dalam pembuatan suatu busana, karena pola merupakan jiplakan bentuk badan yang digambar sesuai dengan ukuran badan seseorang yang diukur secara cermat dan tepat. Pola busana wanita dengan bentuk tubuh gemuk memerlukan sistem pola khusus dibandingkan dengan wanita dengan bentuk tubuh ideal. Penelitian ini bertujuan untuk melihat kelemahan, cara memperbaiki, kesesuaian pola dasar sistem Indonesia untuk wanita Indonesia dengan bentuk tubuh gemuk. Penelitian ini merupakan penelitian terapan, objek penelitiannya yaitu pola dasar sistem indonesia yang di fitting sebanyak tiga kali pada wanita dewasa dengan bentuk tubuh gemuk, dengan tiga panelis yaitu dosen yang ahli dibidang pembuatan pola. Teknik pengumpulan data penelitian ini diperoleh dengan menyebarkan instrumen penelitian yang disusun berdasarkan kuesioner atau angket berupa skala likers, sedangkan teknik analisis data yang digunakan yaitu, modus, median dan persentase untuk menetukan kecenderungan terbanyak dalam penilaian kesesuaian pola dasar sistem Indonesia pada wanita dengan bentuk tubuh gemuk. Hasil penelitian, menunjukkan bahwa pola dasar sistem Indonesia terdapat kelemahan dengan persentase $71 \%$ dan diklasifikasikan dengan kategori sesuai. Perbaikan dengan persentase $95 \%$ dengan klasifikasi sangat sesuai. Secara keseluruhan pola dasar sistem Indonesia setelah dilakukan penyesuaian diperoleh persentase $95 \%$ dan diklasifikasikan dengan kategori sangat sesuai untuk wanita dengan bentuk tubuh gemuk.
\end{abstract}

Kata Kunci: pola Indonesia, wanita, gemuk

\begin{abstract}
Making fashion patterns is one of the most important processes in making clothes, because the pattern is a copy of the body shape drawn in accordance with the size of a person's body that is measured carefully and precisely. Women's clothing patterns with fat body shapes require a special pattern system compared to women with ideal body shape. This study aims to see weaknesses, ways to improve, the suitability of the basic pattern of the Indonesian system for Indonesian women with a fat body shape. This research is an applied research, the object of the research is the basic pattern of the Indonesian system that has been fitted three times in adult women with obese bodies, with three panelists namely lecturers who are experts in pattern making. The data collection technique of this research was obtained by distributing research instruments compiled based on questionnaires in the form of likers scale, while the data analysis techniques used were, mode, median and percentage to determine the most trends in assessing the suitability of the Indonesian system's basic pattern in women with obese bodies. The results of the study indicate that the basic pattern of the Indonesian system has weaknesses with a percentage of $71 \%$ and classified in the appropriate category. Repairing with a percentage of $95 \%$ with classification is very appropriate. Overall the basic pattern of the Indonesian system after adjustments was obtained was a percentage of $95 \%$ and classified with a category very suitable for women with fat body shape.
\end{abstract}

Keywords: pattern of Indonesia, women, obese bodies.

\section{PENDAHULUAN}

Dalam pembuatan busana diperlukan adanya pola, karena dengan adanya pola akan mudah dalam pembuatan suatu pakaian. Cara pembuatan pola dasar merupakan suatu pengetahuan dan ketrampilan yang penting dan mutlak harus dikuasai oleh pembuat busana. Kecocokan suatu pola dasar pada bentuk tubuh tertentu akan sangat berpengaruh terhadap hasil 
pembuatan pakaian. Menurut Muliawan (2011:2) "Pattern atau pola dalam bidang jahit - menjahit dimaksudkan suatu potongan kain atau potongan kertas, yang dipakai sebagai contoh untuk membuat baju. Potongan kain atau kertas tersebut mengikuti ukuran bentuk badan tertentu, sedangkan menurut Pratiwi (2001) “ pola adalah potongan-potongan kertas yang merupakan prototype bagian-bagian pakaian atau produk jahit-menjahit”. Ada beberapa macam cara yang dapat digunakan untuk membuat pola dasar busana ditinjau dari jenis pola antara lain pola cetak, pola standart dan pola konstruksi.

Pola konstruksi untuk wanita bermacam-macam sistemnya, diantaranya pola dasar Soen, pola dasar Dressmaking, pola dasar Danckaerts, pola dasar Charmant, pola dasar Cuppens Geurs, pola dasar Bunka, dan pola dasar Meyneke. Mengingat seluruh sistem pola dasar dikembangkan oleh pakar-pakar busana dari luar Indonesia, dengan ukuran-ukuran tubuh sesuai dengan negaranya maka pola tersebut jarang sekali diterapkan secara murni, salah satunya yaitu sistem pola dasar Indonesia yang dikembangkan oleh Porrie Muliawan. Porrie Muliawan adalah seseorang yang berpengalaman dibidang jahit menjahit dan konstruksi pola. Beliau mengajar dibidang PKK di IKIP Jakarta dan Beliau mendapatkan pendidikan formal dari training-training.

\section{KAJIAN TEORI}

\section{Pola Dasar}

Pola dasar merupakan kutipan bentuk badan manusia yang asli atau pola yang belum diubah, (Pratiwi, 2001:3). Pembuatan pola dasar merupakan pengetahuan dan ketrampilan yang penting dan wajib di kuasai oleh seseorang yang berkecimpung dibidang busana terutama dibidang konstruksi pola. Sebelum digunakan sebagai contoh untuk menggunting kain pola dasar busana akan edit atau di luar Negeri, seperti Workshop Of The Trend Of Home Economic Education, dan Workshop Of Family Life Education Di Amerika Serikat. Beliau juga mendapatkan penghargaan dari ISWI (Ikatan Sarjana Wanita Indonesia) sebagai pendidik di bidang busana sejak tahun 1945 hingga pensiun di tahun 1997. Pola dasar sistem Indonesia menurut Prahastuti (2007:28) Pola dasar sistem Indonesia merupakan pola dasar kombinasi antara pola Meyneke dan pola dressmaking, untuk pola badan menggunakan sistem Meyneke, lengan dengan sistem Dressmaking, sedangkan untuk rok menggunakan kombinasi antara pola Meyneke dan Deressmaking.
Gorga Jurnal Seni Rupa

Volume 08 Nomor 01 Januari-Juni 2019

p-ISSN: 2301-5942 | e-ISSN: 2580-2380

Berdasarkan uji coba awal yang penulis lakukan pada wanita bertubuh ideal untuk mengetahui pas tidaknya pola pada badan. Hasil dari uji coba sistem pola tersebut untuk wanita bertubuh ideal diketahui letak garis badan tepat,namun garis bahu cenderung kearah belakang dan untuk lingkar lubang lengan terlalu longgar dan garis sisi bergeser kebelakang. Hal ini sejalan dengan pendapat Prahastuti (2007:31) telah menganalisis pola dasar pakaian wanita sistem Meyneke untuk berbagai bentuk tubuh mahasiswa. Penelitian tersebut mengungkapkan bahwa ketepatan titik-titik pas (fitting factor) untuk pola tersebut hanya cocok untuk bentuk tubuh gemuk, sedangkan untuk bentuk tubuh kurus dan ideal titik-titik pas tidak tepat berada di bagian yang seharusnya.

Oleh karena itu pola dasar sistem Indonesia kemungkinan lebih tepat digunakan untuk wanita yang mempunyai ukuran badan lebih besar seperti wanita yang bertubuh gemuk. diubah sesuai dengan desain yang telah dirancang untuk membuat pakaian. Menurut Noor (2015:54) "Pola merupakan ciplakan bentuk badan yang biasa dibuat diatas kertas, yang nanti dipakai sebagai contoh untuk menggunting pakaian seseorang. Potongan kertas tersebut dibuat mengikuti ukuran badan seseorang dan dijadikan contoh agar tidak terjadi kesalahan pada saat menggunting. Sedangkan menurut Pratiwi (2001:3) "Pattern atau pola dalam bidang jahit menjahit adalah suatu potongan kain atau kertas yang dipakai sebagai contoh untuk membuat baju, pada saat kain digunting".

Berdasarkan pendapat diatas dapat disimpulkan bahwa pola merupakan ciplakan bentuk badan seseorang yang dibuat diatas kain atau kertas yang menggunakan ukuranukuran tertentu dan dijadikan sebagai contoh pada saat menggunting kain supaya tidak terjadi kesalahan. Berdasarkan teknik pembuatannya, pola dasar dibagi menjadi dua. Menurut Pratiwi (2001:3) yaitu “ Pola dasar draping dan pola dasar yang dibuat dengan konstuksi atau flat pattern. Menurut Muliawan (2011:1) Pola konstruksi adalah pola dasar yang dibuat berdasarkan ukuran badan sipemakai dan digambar dengan perhitungan secara matematika sesuai dengan sistem pola masing-masing. sejalan dengan itu menurut Syafri (2007:7) "pola konstruksi adalah pola yang dibuat berdasarkan ukuran perorangan atau khusus dibuat untuk seseorang dan cara pengambilan ukuran serta perhitungannya sesuai dengan sistem pola dasar yang digunakan”. Berdasarkan pendapat diatas dapat disimpulkan bahwa pola konstruksi adalah pola yang dibuat diatas kertas dengan ukuran badan seseorang atau model menggunakan sistem pola tertentu dan diperhitungkan secara matematika sehingga tergambar bentuk badan, biasanya dijadikan contoh untuk memotong bahan. 


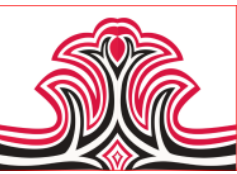

\section{Teknik Mengambil Ukuran}

Pembuatan pola dasar dengan teknik konstruksi maupun teknik komputer memerlukan ukuran badan yang digunakan sebagai acuan dalam pembuatan pola dasar. Sebelum mengambil ukuran badan seseorang harus memperhatikan bentuk bahu, badan, pinggang dan panggul karena pada bagian-bagian itu berbeda pada setiap orang. Menurut Soekarno (2002:12) "Seseorang yang akan diukur sebaiknya menggunakan busana yang pas dibadan agar ukuran yang diambil akurat". Pengambilan ukuran dilakukan dengan bantuan pita ukur atau sering disebut dengan meteran, dan pada bagian tertentu dapat digunakan alat bantu berupa pitarban yang diikatkan antara lain pada lingkar badan, lingkar pinggang, dan lingkar. Berdasarkan pendapat diatas dapat disimpulkan bahwa dalam mengambil ukuran banyak yang harus diperhatikan diantaranya yaitu pakaian yang dikenakan sebaiknya pas, sikap model sebaiknya berdiri dengan tegap , dan memberi tanda pada bagian panggul. Sikap sorang yang diambil ukurannya atau model harus berdiri tegak lurus dengan tujuan ukuran yang dihasilkan akurat.

\section{Pembuatan Pola Dasar Sistem Indonesia 1). Pola Badan Muka dan Belakang}
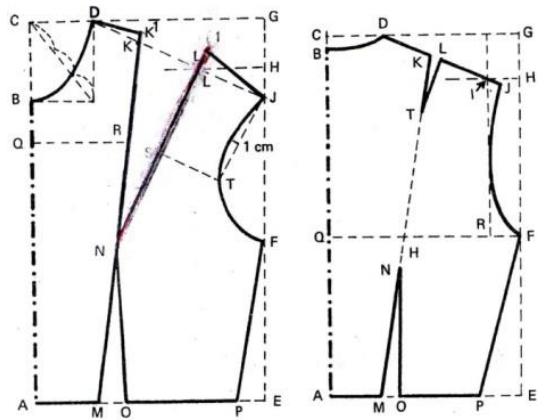

Gambar 1. Pola Muka dan Belakang (Sumber: Muliawan, 2012:9)

$\mathrm{A}-\mathrm{B}=$ Panjang muka

$\mathrm{B}-\mathrm{C}=$ Dalam leher $=1 / 6$ lingkar leher $+2 \frac{1}{2} \mathrm{~cm}$

$\mathrm{C}-\mathrm{D}=$ Lebar leher $=1 / 6$ lingkar leher $+1 / 2 \mathrm{~cm}$

A-E $=1 / 4$ Lingkar badan $+2 \mathrm{~cm}$

$\mathrm{E}-\mathrm{F}=$ Panjang sisi

$\mathrm{C}-\mathrm{G}=\mathrm{A}-\mathrm{E}$

$\mathrm{G}-\mathrm{H}=1 / 3$ panjang bahu $+1 \mathrm{~cm}$

D-I = Panjang bahu, dan titik I harus jatuh pada garis datar dari $\mathrm{H}=$ Garis D-I

\section{Belakang}

A-B $=$ Panjang punggung

$\mathrm{B}-\mathrm{C}=$ Dalam leher $=1 \mathrm{~cm} 1 \frac{1}{2} \mathrm{~cm}$

$\mathrm{C}-\mathrm{D}=$ Lebar leher $=1 / 6$ lingkar leher

$\mathrm{B}-\mathrm{C}-\mathrm{B}-\mathrm{D}=1 / 2$
Gorga Jurnal Seni Rupa

Volume 08 Nomor 01 Januari-Juni 2019

p-ISSN: 2301-5942 | e-ISSN: 2580-2380

$\mathrm{A}-\mathrm{E}=1 / 4$ lingkar badan $-2 \mathrm{~cm}(1 \mathrm{~cm}$ untuk orang kurus)

$\mathrm{E}-\mathrm{F}=$ Panjang sisi

$\mathrm{C}-\mathrm{G}=\mathrm{A}-\mathrm{E}$

$\mathrm{G}-\mathrm{H}=1 / 4 \mathrm{~F}-\mathrm{G}$ kurang $1 \mathrm{~cm}$

D-I = Panjang bahu, titik I jatuh pada garis datar $\mathrm{H}=$ Garis D-I ditarik garis kemudian tambah $1 \mathrm{~cm}$ atau 1 $1 / 2 \mathrm{~cm}$ untuk lipit kup bahu belakang.

D-K = 1/2 Panjang bahu $-1 \mathrm{~cm}$

Dihubungkan hingga garis sisi E-G dan didapat titik J.

$\mathrm{D}-\mathrm{K}=1 / 2$ panjang bahu $-1 \mathrm{~cm}$

$\mathrm{J}-\mathrm{L}=1 / 2$ panjang bahu $+1 \mathrm{~cm}$

$\mathrm{A}-\mathrm{M}=1 / 10$ lingkar pinggang, kemudian Tarik garis

$\mathrm{M}-\mathrm{K}$, hubungkan dengan $\mathrm{K}-\mathrm{K}^{1}=1 / 2 \mathrm{~cm}$

$\mathrm{M}-\mathrm{N}=$ Tinggi dada.

Hubungan dengan garis $\mathrm{N}-\mathrm{L}$ sehingga $\mathrm{NL}^{1}=\mathrm{N}-\mathrm{K}^{1}$

$\mathrm{E}-\mathrm{P}=3 \mathrm{~cm}$

$\mathrm{P}-\mathrm{O}=1 / 4$ lingkar pinggang $+2 \mathrm{~cm}(1 \mathrm{~cm}$ untuk orang

kurus) dikurang jarak A-M

$\mathrm{B}-\mathrm{Q}=4 \mathrm{~cm}$, Tarik garis datar Q-R

Ukur N-R, lalu ukur N-S = N-R

$\mathrm{S}-\mathrm{T}=1 / 2$ lebar muka diukur Q-R (garis $\mathrm{S}-\mathrm{T}$ digambar sejajar garis lanjut D-I) sambungan J-T. Tarik garis bahu D-K dan J-L, garis lipit kup pinggang N-O dan garis lubang lengan seperti contoh.

$\mathrm{J}-\mathrm{L}=1 / 2$ Panjang bahu $+1 \mathrm{~cm}$

$\mathrm{A}-\mathrm{M}=1 / 10$ lingkar pinggang $-1 \mathrm{~cm}$ tarik garis $\mathrm{M}-\mathrm{K}$ titik $\mathrm{N}$ letaknya $4 \mathrm{~cm}$ di bawah garis datar dari $\mathrm{F}$.

$\mathrm{M}-\mathrm{O}=2 \mathrm{~cm}$ untuk lipit krup pinggang

$\mathrm{O}-\mathrm{P}=1 / 4$ Lingkar pinggang $-2 \mathrm{~cm}$ (orang kurus $1 \mathrm{~cm}$ ) dikurung jarak A-M.

$\mathrm{F}-\mathrm{Q}=$ Garis datar

$\mathrm{Q}-\mathrm{R}=1 / 2$ Lebar punggung

Tarik garis R-S tegak lurus dan bentuk lubang lengan seperti contoh. Tarik garis lipit kup N-O.

$\mathrm{K}-\mathrm{T}=6 \mathrm{~cm}$ panjang kup bahu tarik garis L-T

B-C-B-D = $1 / 2$ lingkar lubang lengan

$\mathrm{B}-\mathrm{E}=$ Panjang lengan panjang $=51 \mathrm{~cm}$

$\mathrm{F}-\mathrm{G}=\mathrm{C}-\mathrm{D}=$ Garis bawah lengan garis $\mathrm{C}-\mathrm{F}$ dan $\mathrm{D}-\mathrm{G}$ tengak lurus. 


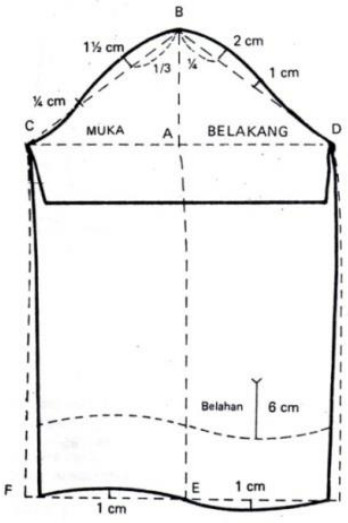

Gambar 2. Pola Dasar Lengan (Sumber: Muliawan, 2012:12)

\section{Keterangan Cara Membuat Pola Dasar Lengan Sistem Porrie Muliawan:}

1. Tarik garis datar tidak diukur.

Ambil satu titik ditengah-tengah, titik A. Ukur A-B

$=$ Tinggi Kepala Lengan,

2. Dari F dan $G$ diukur masuk $1 \mathrm{~cm}$,

3. Bagi garis miring $\mathrm{B}-\mathrm{C}$ dalam 3 bagian dan garis miring B-D dalam 4 bagian'

4. Pada $1 / 3$ bagian dari $\mathrm{B}$ dikukur ke atas $1 \frac{1 / 2}{\mathrm{~cm}}$ dan pada $1 / 4$ bagian dari B diukur $1 \frac{1}{2}$ atau $2 \mathrm{~cm}$ dan pada pertengahan,

5. B-D diukur ke atas $1 \mathrm{~cm}$. pada tengah $1 / 3 \mathrm{~B}-\mathrm{C}$ dari C diukur ke bawah $1 / 2 \mathrm{~cm}$ atau $1 / 4 \mathrm{~cm}$,

6. Bentuk kerung lengan sesuai dengan gambar menurut contoh melalui titik-titik yang telah diukur, dan

7. Bagian bawah lengan dari lengan panjang dibentuk seperti gambar, yaitu bagian muka dilengkungkan $1 \mathrm{~cm}$ bagian belakang dibulatkan $1 \mathrm{~cm}$ ke bawah.

\section{3). Pola Dasar Rok}

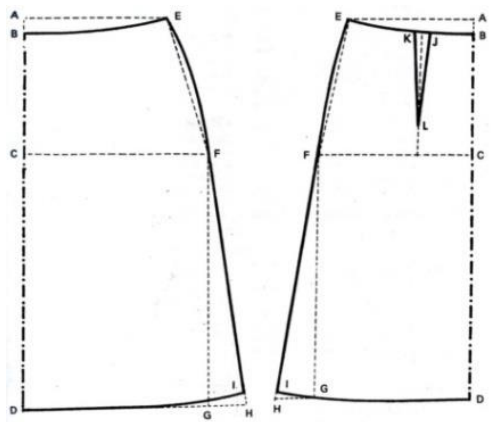

Gambar 3. Pola Dasar Rok Muka dan Belakang (Sumber: Muliawan, 2012:12)
$\mathrm{G}-\mathrm{H}=5 \mathrm{~cm}$

E-F-I = panjang rok sisi

Gambar garis pinggang datar terlebih dahulu, hubungkan titik B dan $\mathrm{E}$ dengan garis lurus kemudian menggunakan rol pola lengkung. Kemudian buat lah garis sisi melalui titik E-F dengan garis lurus dan di tambah $1 \mathrm{~cm}$ diantara E-F. Kemudian bentuk panggul dengan menggunakan rol melengkung.

\section{Belakang}

$\mathrm{A}-\mathrm{B}=2 \mathrm{~cm}$

$\mathrm{B}-\mathrm{C}=$ tinggi panggul

$\mathrm{B}-\mathrm{D}=$ panjang rok belakang

$\mathrm{A}-\mathrm{E}=1 / 4$ lingkar pinggang $-2 \mathrm{~cm}$ atau $1 \mathrm{~cm}$ disesuaikan dengan badan ditambah $2 \mathrm{~cm}$ untuk kup, karena belakang harus menggunakan lipit kup.

$\mathrm{D}-\mathrm{G}=\mathrm{C}-\mathrm{F}$

$\mathrm{G}-\mathrm{H}=5 \mathrm{~cm}$

E-F-I = panjang sisi rok

$\mathrm{B}-\mathrm{J}=1 / 10$ lingkar pinggang dikurang $1 \mathrm{~cm}$ seperti pinggang badan bagian belakang

$\mathrm{J}-\mathrm{K}=2 \mathrm{~cm}$, lipit kup

\section{Bentuk Tubuh Wanita Indonesia}

Salah satu unsur yang harus diperhatikan dalam pembuatan busana selain daripada pola adalah model atau desain. Karena tidak semua sistem pola dan model cocok untuk semua bentuk tubuh. Pada umumnyaa bentuk tubuh setiap manusia berbeda satu dan lainnya. Hal ini disebabkan oleh banyak faktor antara lain faktor fisik berdasarkan keturunan, suku, ras dan perkembangan fisik karena faktor dari makanan. Menurut Poespo (2000:40) mengatakan bahwa " Desain badan kita ditentukan oleh faktor keturunan (genetik) dan pengaruh makanan serta lingkungan hidup kita. Sedangkan menurut Moerliono (1995:25) mengatakan bahwa "bentuk dan ukuran tubuh merupakan gambaran atau keseluruhan jasad manusia yang kelihatan dari ujung rambut sampai ujung kaki.

Berdasarkan pendapat diatas dapat disimpulkan bahwa manusia memiliki bentuk tubuh, ukuran, tinggi dan portur tubuh yang berbeda antara satu dan yang lainnya. Bentuk tubuh dipengaruhi oleh beberapa faktor antara lain faktor keturunan, faktor makanan, dan faktor lingkungan hidup.

Menurut Pratiwi (2001:6-7) Bentuk tubuh manusia digolongkan menjadi lima macam bentuk tubuh yaitu : (a). Bentuk tubuh normal atau ideal, dengan tinggi 160 $\mathrm{cm}-164 \mathrm{~cm}$. (b). Bentuk tubuh gemuk pendek, dengan tinggi. 


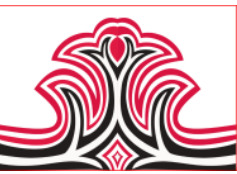

Selain itu untuk mengetahui berat badan ideal dapat digunakan rumus Key, seperti yang dikemukakan oleh Ramayulis (2008:7) sebagai berikut:

\section{Berat Badan Ideal $=\{\text { Berat Badan }(M)\}^{2}$ X 20,9}

$150 \mathrm{~cm}-160 \mathrm{~cm}$. (c). Bentuk tubuh kurus pendek, dengan tinggi $150 \mathrm{~cm}-160 \mathrm{~cm}$. (d). Bentuk tubuh tinggi gemuk, dengan tinggi $165 \mathrm{~cm}-170 \mathrm{~cm}$. (e). Bentuk tubuh tinggi kurus, dengan tinggi $165 \mathrm{~cm}-170$ cm. Sedangkan menurut Soerya (2012) mengatakan bahwa :

(1). Ideal, sesorang dikatakan memiliki bentuk tubuh ideal, jika perbandingan antara tinggi dan berat badannya seimbang. Bentuk tubuh ini sangat diinginkan setiap orang, karena jika memakai busana apapun akan terlihat pantas dan menarik, (2) kurus, seseorang dikatakan memiliki bentuk tubuh kurus jika berat badannya kurang dari berat ideal, (3) Gemuk, seseorang dikatakan memiliki bentuk tubuh gemuk, jika berat badannya lebih dari berat ideal.

Berdasarkan pendapat diatas dapat disimpulkan bahwa bentuk tubuh wanita dapat digolongkan menjadi lima antara lain wanita yang bertubuh normal atau ideal, wanita yang memiliki bentuk tubuh kurus tinggi, wanita bertubuh gemuk tinggi,wanita bertubuh kurus pendek, dan wanita bertubuh gemuk pendek. Wanita dikatakan gemuk pendek apabila wanita tersebut memiliki berat badan lebih dari berat ideal dengan tinggi badan $150 \mathrm{~cm}$ sampai $160 \mathrm{~cm}$.

Menurut Sunardi (2012:54) mengatakan bahwa cara sederhana menghitung berat badan ideal :

Menggunakan Body Mass Index atau Indeks Massa Tubuh (IMT)

\section{IMT $=\underline{\text { Berat Badan }(\mathbf{k g})}$ TB (m) x TB (m)}

Berdasarkan rumus tersebut di atas dapat diketahui bahwa seseorang yang memiliki tinggi $155 \mathrm{~cm}$ akan memiliki berat badan ideal terbesar $1,55 \times 1,55$ x 20,9 $=50 \mathrm{~kg}$. adapun kategori bentuk tubuh menurut WHO, yaitu:

Tabel 1. Klarifikasi Indeks Massa Tubuh

\begin{tabular}{|c|c|}
\hline Classifications & $\begin{array}{c}\text { Bmi(Kg/M } \\
\text { Principal Cut-Off } \\
\text { Points }\end{array}$ \\
\hline Underweigt & $<\mathbf{1 8 , 5 0}$ \\
Severe Thinness & $16,00-16,99$ \\
Moderate Thinness & $17,00-18,49$ \\
Mild Thinness & $\mathbf{1 8 , 5 0 - 2 5 , 9 9}$ \\
\hline Normal Range & $\mathbf{2 5 , 9 9 - 2 9 , 9 9}$ \\
\hline Pre Obese & $>\mathbf{3 0 , 0 0}$ \\
Obese & $30,00-34,99$ \\
Obese Class I & $35,00-39,99$ \\
Obese Class II & $>40,00$ \\
\hline Obese Classii & \\
\hline Sumber: WHO, 2004 &
\end{tabular}

Gorga Jurnal Seni Rupa

Volume 08 Nomor 01 Januari-Juni 2019

p-ISSN: 2301-5942 | e-ISSN: 2580-2380

Dapat kita simpulkan bahwa wanita dengan tinggi badan $155 \mathrm{~cm}$ berat badan idealnya adalah $50 \mathrm{~kg}$. Karena bentuk badan ideal merupakan seimbangnya antara berat badan dan tinggi badan. Merujuk dari beberapa pendapat para ahli, maka penelitian memilih model dengan berat badan $85 \mathrm{~kg}$ dan tinggi badan 155 cm dengan IMT $(\mathrm{kg} / \mathrm{m})$ diperoleh 35 dan tergolong gemuk obesitas tingkat II

\section{Penyesuaian Pola Sistem Indonesia Porrie Muliawan}

Kesesuaian menurut Hasan (2007: 1093) adalah “ kecocokan keselarasan". Jadi, dapat disimpulkan dalam penelitian ini adalah kecocokan antara Pola Dasar Sistem Indonesia Porrie Muliawan untuk wanita dengan bentuk tubuh gemuk.

Dalam menyesuaikan Pola Dasar Sistem Indonesia untuk wanita yang memiliki bentuk tubuh gemuk pendek, maka perlu dilakukan Fitting atau pengepasan. Menurut Poespo (2000:72) menyatakan bahwa " Fitting menunjukkan pada sempit dan longgarnya sebuah bentuk busana dalam hubungannya dengan yang memakainya". Sedangkan menurut Hutton (1973:3) yaitu "Fitting adalah mengepas atau mencocokkan antara ukuran dengan pola, kemudian try out pada bahan katun, mengepas pada badan sipemakai.

Dari pendapat diatas dapat disimpulkan bahwa Fitting adalah mengepas busana yang dibuat pada badan sipemakai, fitting dilakukan agar busana yang akan dipakaipas badan, tidak besar, tidak kecil dan nyaman ketika dipakai. Setelah melakukan Fitting pada badan sipemakai untuk mengevaluasi hasil try out, selanjutnya memperbaiki kelemahan pola dan menyesuaikannya.

Dalam penelitian ini penulis menyesuaikan pola dasar sistem yang terdapat pada buku Winifred Aldrich, karena di dalam buku Porrie Muliawan tidak terdapat cara untuk menyesuaikan kelemahan-kelemahan pada pola dasar sistem Indonesia.

\section{METODE PENELITIAN}

Berdasarkan permasalahan-permasalahan yang ditemukan, maka penelitian ini merupakan penelitian terapan. Menurut Nawawi dan Martini (1996:25) mengatakan bahwa "Penelitian terapan dilakukan untuk mengunkapkan keadaan yang sebenarnya (apa adanya) dari objek yang diselidikinya agar mengungkapkan kekurangannya, yang akan menjadi dasar dalam menyusun langkah-langkah terbaik dan penyempurnaannya. Sejalan dengan itu, Sugiyono 
(2009:9) mengatakan bahwa "penelitian terapan dilakukan dengan tujuan menerapkan, menguji, dan mengevaluasi kemampuan suatu teori yang ditetapkan dalam memecahkan masalah praktis. Instrumen yang digunakan dalam penelitian ini adalah menggunakan kuesioner atau angket. Skala yang digunakan yaitu skala Likers.

Untuk melakukan uji coba Instrumen menggunakan validitas logis dan validitas konstrak, sedangkan kontrol validasi dilakukan dengan cara menggunakan bahan blacu, pengambilan ukuran sesuai dengan sistem pola, setiap langkah pembuatan pola diperiksa ketepatan ukuran, penilaian dilakukan dengan cara menyesuaikan uji coba pola dasar sistem Indonesia untuk wanita dengan tubuh gemuk, penilaian dilakukan oleh 3 panelis yang ahli dibidang pola konstruksi, pada item yang sudah sangat sesuai (skor 4) dan pada item yang sudah sesuai (skor 3), penilaian tidak perlu lagi dilakukan untuk fitting selanjutnya.

Untuk menganalisa data dalam penelitian ini menggunakan analisis statis deskriptif . Menurut Irawan (2011:85) mengatakan bahwa " Alat statistik yang bisa dipakai untuk menggambarkan profil statistik satu variabel sebagai berikut:

Tabel 2. Alat Statistik

\begin{tabular}{|c|c|c|}
\hline Jenis Data & Alat Statistik & Penjelasan \\
\hline Ordinal & $\begin{array}{l}\text {-Modus } \\
\text {-Median (Md) } \\
\text {-Persentase }(\%)\end{array}$ & $\begin{array}{l}\text { - Untuk } \\
\text { menjelaskan } \\
\text { kecenderungan } \\
\text { terbanyak } \\
\text { - Untuk } \\
\text { menjelaskan } \\
\text { kecenderungan } \\
\text { tengah } \\
\text { - Untuk } \\
\text { menjelaskan } \\
\text { proporsi data dalam } \\
\text { persentase }(\%)\end{array}$ \\
\hline
\end{tabular}

Data diolah dengan menggunakan program Microsoft Excel, kemudian data yang diperoleh dikelompokkan dalam 5 kategori standar penilaian yang dikemukakan oleh Sugiono (2009) yaitu:

Tabel 3. Kategori Standar Penilaian

\begin{tabular}{|c|c|c|}
\hline No & Persentase & Kategori \\
\hline 1 & $20 \%-35,99 \%$ & Sagat tidak sesuai \\
\hline 2 & $40 \%-51,99 \%$ & Tidak sesuai \\
\hline 3 & $52 \%-67,99 \%$ & Cukup sesuai \\
\hline 4 & $68 \%-83,99 \%$ & Sesuai \\
\hline 5 & $84 \%-100 \%$ & Sangat sesuai \\
\hline
\end{tabular}

\section{HASIL DAN PEMBAHASAN}

\section{Hasil}

Dalam penelitian kesesuaian pola dasar sistem Indonesia pada wanita bertubuh gemuk, terlebih dahulu dilakukan pengambilan ukuran, membuat pola
Gorga Jurnal Seni Rupa

Volume 08 Nomor 01 Januari-Juni 2019

p-ISSN: 2301-5942 | e-ISSN: 2580-2380

dan seterusnya membuat baju yang kemudian dilakukan oleh 3 orang panelis yaitu dosen tata busana IKK FPP UNP yang ahli dalam bidang pola dengan cara fitting / pengepasan yang bertujuan untuk mengetahui kelemahan, bagian - bagian yang perlu disesuaikan, cara menyesuaikan serta kesesuaian dari pola dasar sitem Indonesia untuk wanita bertubuh gemuk. Aspek yang dinilai terdiri dari 27 ukuran.

Berdasarkan analisis data yang telah dilakukan, maka pada kelemahan pola dasar sistem Indonesia dapat di fitting I, persentase pada indikator pola dasar badan sebesar $67 \%$ dengan kategori cukup sesuai, pola dasar lengan dengan persentase $91,7 \%$ dengan kategori sangat sesuai, dan pola dasar rok dengan persentase $63 \%$ dikategorikan cukup sesuai.

Hal ini dapat dilihat bahwa sebagian besar pola dasar sistem Indonesia sudah memiliki kesesuaian, akan tetapi masih ada sebagian yang lainnya dikategorikan kurang sesuai, maka kelemahan pola tersebut perlu diperbaiki. Dari penjelasan tersebut sejalan dengan pendapat Muliawan (2011:7) bahwa "dari pemakaian pola konstruksi terdapat keburukan, yaitu pola konstruksi tidak mudah digambar, waktu yang diperlukan lebih lamadari memakai pola jadi dan membutuhkan latihan lama”.

Pada indikator pola dasar sistem Indonesia diperbaiki sebelum melakukan fitting II. Perbaikkan tersebut dilakukan dengan cara : untuk indikator badan (lebar muka dikurangi $1 \mathrm{~cm}$, panjang muka ditambah 1 $\mathrm{cm}$,tinggi puncak dada dikurang $1 \mathrm{~cm}$, lebar dada dikurang $0,75 \mathrm{~cm}$, panjang punggung ditambah $0,5 \mathrm{~cm}$, garis sisi bergeser $1,5 \mathrm{~cm}$, panjang sisi ditambah $1 \mathrm{~cm}$ ). Untuk indikator pola rok (lingkar pinggang ditambah $1 \mathrm{~cm}$, lingkar panggul ditambah $2 \mathrm{~cm}$, tinggi panggul turun $1 \mathrm{~cm}$, garis sisi garis sisi bergeser 1,5 $\mathrm{cm}$, panjang sisi kurang $1 \mathrm{~cm}$ ), dan bagian-bagian pola yang dinyatakan sudah sesuai dan tidak perlu dilakukan perbaikan lagi.

Pada indikator penyesuaian pola dasar sistem Indonesia (Fitting III) dilakukan setelah melaksanakan fitting II. Indikator pola dasar badan fitting II persentase $94 \%$ dengan kategori sangat sesuai ,untuk indikator pola lengan persentase $100 \%$ dengan kategori sangat sesuai, dan pola dasar rok pesentase 95\% dengan kategori sangat sesuai.

Hal ini dapat dilihat bahwa sebagian besar pola dasar Indonesia sudah memiliki kesesuaian, akan tetapi masih ada sebagian yang lainnya yang dikategorikan kurang sesuai. Maka dari itu perlu dilakukan 
penyesuaian pola dasar sistem Indonesia pada wanitadengan bentuk tubuh gemuk. Sesuai dengan pendapat Pratiwi (2001:8) bahwa “ dalam proses pembuatan busana, khususnya pada pembuatan pola dan pecah pola,orang dengan bentuk tubuh diluar normal (terutama gemuk) dan orang dengan bentuk tubuh menyimpang,sering disebut displastis memerlukan perlakuan khusus". Untuk mendapatkan perlakuan khusus maka dilakukan penyesuaian pola.

Berdasarkan hasil dari fitting II,maka penyesuaian pola dasar sistem Indonesia pada wanita gemuk dapat dilakukan dengan cara : untuk indikator pola dasar badan (tinggi puncak dada diturunkan $0,5 \mathrm{~cm}$, lebar dada dikurangi $1 \mathrm{~cm}, 0,5 \mathrm{~cm}$ kekanan dan $0,5 \mathrm{~cm}$ kekiri). Setelah dilakukan penyesuaian pola dasar sistem Indonesia pada wanita dengan bentuk tubuh gemuk, maka dilakukan fitting III. Pada fitting III sudah terdapat penyesuaian pola dasar sistem Indonesia untuk wanita dengan tubuh gemuk, dengan persentase yang diperoleh dari penilaian keseleruhan indikator sebanyak 96\% dan diklasifikasikan kedalam kategori sangat sesuai.

\section{Pembahasan}

Persentase untuk pola dasar badan pada fitting pertama yaitu $67 \%$ dengan kategori cukup sesuai, persentase untuk pola dasar lengan yaitu $91,7 \%$ dengan kategori sangat sesuai, dan untuk pola dasar rok yaitu $63 \%$ dengan kategori cukup sesuai. Sedangkan untuk penilaian rata-rata dari seluruh indikator yaitu $71 \%$ dengan kategori sesuai. Akan tetapi, pada fitting pertama ini ditemukan kelemahan pada pola dasar badan dan pola dasar rok, sehingga diperlukan perbaikan.

kelemahan pola dasar sistem Indonesia untuk indikator pola dasar badan ada 7 ukuran yaitu lebar muka, panjang muka, tinggi puncak dada, lebar dada, panjang punggung, garis sisi, panjang sisi, dan untuk indikator pola dasar rok ada 6 ukuran yaitu lingkar pinggang,garis pinggang, lingkar panggul, tinggi panggul, garis sisi dan panjang sisi. Dengan adanya kelemahan-kelemahan yang ada pada fitting I, maka pola harus di perbaiki dan dilakukan fitting kembali.

Data dari indikator pola dasar badan pada fitting pertama dikumpulkan melalui 16 butir item, dan terdapat 7 kelemahan, 7 kelemahan tersebut yaitu lebar muka, panjang muka, tinggi puncak dada, lebar dada, panjang punggung, garis sisi, panjang sisi, dan untuk indikator pola dasar rok ada 6 ukuran yaitu lingkar pinggang,garis pinggang, lingkar panggul, tinggi panggul, garis sisi dan panjang sisi. Dengan
Gorga Jurnal Seni Rupa

Volume 08 Nomor 01 Januari-Juni 2019

p-ISSN: 2301-5942 | e-ISSN: 2580-2380

adanya kelemahan-kelemahan yang ada pada fitting I, maka pola harus di perbaiki dan dilakukan fitting kembali.

Sebelum melakukan perbaikan pola, terlebih dahulu harus mengetahui dan memahami terlebih dahulu tentang ukuran, rumus dan tanda- tanda pola yang digunakan dalam perbaikan pola. Ukuran melingkar dibagi 4, ukuran melebar dibagi 2 dan ukuran panjang tidak dibagi dan untuk tanda - tanda pola yang digunakan dalam memperbaiki pola.

Lebar muka berlebih $2 \mathrm{~cm}$. Hal ini disebabkan karena dalam pembuatan pola ukuran lebar muka tidak dilakukan pemeriksaan kembali. Cara memperbaiki pola yaitu dengan mengurangilebar bahu sebanyak 2 $\mathrm{cm}$, artinya $1 \mathrm{~cm}$ kanan dan $1 \mathrm{~cm}$ kiri

Panjang muka kurang $1 \mathrm{~cm}$. Hal ini dikarenakan ukuran tidak tepat dan dan tidak dilakukan pengecekan kembali pada saat pembuatan pola. cara memperbaiki pola yaitu dengan menambah panjang muka sebanyak $1 \mathrm{~cm}$.

Tinggi puncak dada naik $1 \mathrm{~cm}$. Hal ini disebabkan karena pemakaian Buste Houder $(\mathrm{BH})$ yang berbeda pada saat pengambilan ukuran dan pada saat fitting 1 . Cara memperbaikinya yaitu dengan cara menurunkan tinggi puncak dada sebanyak $1 \mathrm{~cm}$, kemudian perbaiki garis tinggi puncak dada.

Lebar dada bergeser keluar sebanyak $0,75 \mathrm{~cm}$. Hal ini disebabkan karena pemakaian Buste Houder (BH) yang berbeda pada saat pengambilan ukuran dan pada saat fitting 1. Cara memperbaiki lebar dada tersebut yaitu dengan mengeser lebar dada ke dalam atau kearah tengah muka sebanyak $0,75 \mathrm{~cm}$.

Panjang punggung naik/ kurang 0,5 cm. Hal ini dikarenakan pada saat pengambilan ukuran. Cara memperbaiki panjang punggung yaitu dengan cara mengurangi panjang punggung $0,5 \mathrm{~cm}$.

Garis sisi bergeser kebelakang 1,5 cm. Karena pola pola depan dan belakang selisih lebih dari $3 \mathrm{~cm}$. Cara memperbaiki pola tersebut yaitu dengan mengurangi garis sisi muka sebanyak $0,75 \mathrm{~cm}$, dan menambah garis sisi belakang sebanyak $0,75 \mathrm{~cm}$.

Panjang sisi kurang $1 \mathrm{~cm}$. Karena pada saat pengambilan ukuran dan pembuatan pola tidak diperiksa kembali. Cara memperbaikinya yaitu dengan cara menambah panjang sisi. 
Lingkar pinggang sempit atau kurang $1 \mathrm{~cm}$. Hal ini dikarenakan kurang tepatnya pengambilan ukuran. Cara memperbaikinya yaitu dengan cara menambah $0,25 \mathrm{~cm}$ pada pola dasar muka dan belakang.

Garis pinggang kurang tepat atau naik $1 \mathrm{~cm}$. Hal ini dikarenakan panjang muka, panjang sisi, dan panjang punggung yang kurang tepat. Cara memperbaikinya yaitu dengan cara memperbaiki garis pinggang pada pola dasar badan.

Lingkar panggul sempit $2 \mathrm{~cm}$ hal ini dikarenakan pengukuran tidak tepat. Cara memperbaikinya yaitu dengan menambah lingkar panggul muka sebanyak $0,5 \mathrm{~cm}$ dan belakang sebanyak $0,5 \mathrm{~cm}$.

Tinggi panggul naik $1 \mathrm{~cm}$. Hal ini dikarenakan penambahan panjang punggung, sehingga mempengaruhi letak tinggi panggul. Cara memperbaiki tinggi panggulyaitu dengan cara menambah tinggi panggul sebanyak $1 \mathrm{~cm}$.

Garis sisi rok bergeser kebelakang sebanyak 1,5 cm. Hal ini karena penambahan dan pengurangan antara pola muka dan belakang berselisih $1,5 \mathrm{~cm}$. Cara memperbaiki polanya yaitu dengan cara mengurangi garis sisi muka pada bagian pinggang hingga bawah rok sebanyak $1,5 \mathrm{~cm}$ dan menambah garis sisi belakang bagian pinggang hingga bawah rok sebanyak $1,5 \mathrm{~cm}$.

Panjang sisi rok naik $1 \mathrm{~cm}$. Karena lingkar panggul sempit sehingga menyebabkan panjang sisi rok naik. Cara yang dilakukan untuk memperbaiki pola tersebut yaitu dengan menambah panjang sisi rok.

Setelah dilakukan penyesuaian pola dasar sistem Indonesia pada wanita dengan bentuk tubuh gemuk pola dasar sistem Indonesia, maka dilakukan fitting III guna melihat kesesuaian pola dasar tersebut pada wanita dengan bentuk tubuh gemuk.

Berdasarkan data yang didapat pada fitting III dapat dilihat bahwa persentase untuk penyesuaian pola dasar sistem Indonesia pada wanita bertubuh gemuk pada fitting III yaitu sebesar $95 \%$ dengan kategori sangat sesuai, persentase dari pola dasar badan yaitu $93 \%$ dengan kategori sangat sesuai, pola dasar lengan $100 \%$ dengan kategori sanga sesuai, pola dasar rok 96\% dengan kategori sangat sesuai. Dari penjelasan diatas dapat disimpulkan bahwa pada Pola sistem Indonesia dapat dipakai untuk wanita dengan bentuk tubuh gemuk.
Gorga Jurnal Seni Rupa

Volume 08 Nomor 01 Januari-Juni 2019

p-ISSN: 2301-5942 | e-ISSN: 2580-2380

\section{KESIMPULA DAN SARAN}

\section{Kesimpulan}

Berdasarkan analisis data dan pembahasan maka penulis mengambil kesimpulan bahwa terdapat kelemahan. Setelah diuji coba, dan diperoleh hasil data berdasarkan persentase untuk indikator kelemahan pola dasar badan yaitu $67 \%$ dengan kategori cukup sesuai, indikator pola dasar lengan 91,7 dengan kategori angat tinggi, dan untuk pola dasar rok $63 \%$ dengan kategori cukup sesuai. Sedangkan persentase secara keseluruhan maka didapat $71 \%$ dengan kategori cukup sesuai.

Penyesuaian pola dasar sistem Indonesia pada wanita dengan bentuk tubuh gemuk, dilakukan setelah fitting II atau setelah mengetahui kelemahan serta cara memperbaiki pola dasar sistem Indonesia. Sehingga terdapat beberapa rumusan pola yang perlu diperbaiki dan disesuaikan agar pola dasar sistem indonesia cocok digunakan untuk wanita bertubuh gemuk.

Berdasarkan hasil temuan penelitian pada fitting kedua ,setelah diuji coba, dan diperoleh hasil data berdasarkan persentase untuk indikator penyesuian pola dasar badan yaitu $94 \%$ dengan kategori sangat sesuai, indikator pola dasar lengan 100 dengan kategori angat tinggi, dan untuk pola dasar rok $95 \%$ dengan kategori cukup sesuai. Sedangkan persentase secara keseluruhan maka didapat $95 \%$ dengan kategori sangat sesuai sesuai.

Hasil temuan penelitian pada fitting III ,setelah diuji coba, dan diperoleh hasil data berdasarkan persentase untuk indikator penyesuian pola dasar badan yaitu 94 $\%$ dengan kategori sangat sesuai, indikator pola dasar lengan 100 dengan kategori angat tinggi, dan untuk pola dasar rok $96 \%$ dengan kategori cukup sesuai. Sedangkan persentase secara keseluruhan maka didapat $95 \%$ dengan kategori sangat sesuai untuk wanita dengan bentuk tubuh gemuk. Berdasarkan kesimpulan diatas, maka dikemukakan beberapa saran sebagai berikut:

\section{Saran}

Mahasiswa PKK tata busana agar dapat menggunakan pola dasar sistem Indonesia yang terdapat pada penelitian ini, karena pola dasar tersebut telah disesuaikan untuk wanita bertubuh gemuk. Mahasiswa Jurusan IKK dapat menjadi bahan bacaan atau literature untuk menambah khasanah ilmu pengetahuan. Dosen IKK dapat menjadi bahan bacaan dan literasi untuk dipraktekan pada matakuliah konstruksi pola busana. Masyarakat dapat menggunakan pola dasar sistem Indonesia, karena 


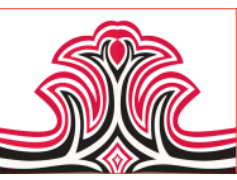

pola dasar sistem Indonesia sangat sesuai untuk wanita dengan bentuk tubuh gemuk dengan usia 30 40 tahun yang sudah menikah dan pernah melahirkan. Masyarakat dapat menggunakan pola dasar sistem Indonesia, untuk wanita dengan bentuk tubuh ideal akan tetapi terdapat kelemahan,yaitu garis bahu bergeser kebelakang. Cara memperbaikinya yaitu dengan cara mengurangi bahu bagian depan dan menambah bahu bagian belakang. Peneliti selanjutnya agar dapat melanjutkan penelitian pola dasar sistem Indonesia dengan bentuk tubuh ideal.

\section{DAFTAR RUJUKAN}

Hasan, Alwi. (2007). Kamus Lengkap Bahasa Indonesia Modern. Jakarta: Balai Pustaka.

Hutton, Jessie. (1973). Fashion Tailoring. New York: Golden Press.

Irawan, Adi. (2011). Modul Praktikum Statistika 1. Semarang: Cipta Prima Nusantara Semarang.

Moerliono, Anton. (1995). Kamus Besar Bahasa Indonesia. Jakarta: Depdikbud.

Muliawan, Porrie. (2011). Konstruksi Pola Busana Wanita. Jakarta: Libri.

Nawawi, Hadiri \& Martini, Mimi. (1996). Penelitian Terapan. Yogyakarta: Gadjah Mada University Press.

Noor, Juliansyah. (2015). Metode Penelitian. Jakarta: Prenada Media Group.

Prahastuti, Endang. (2007). Analisis Pola Dasar Pakaian Sistem Meyneke Pada Berbagai Bentuk Tubuh Mahasiswa. Malang: Pusat Penelitian IKIP Malang.

Pratiwi, Djati. (2001). Pola Dasar dan Pecah Pola Busana. Yogyakarta: Penerbit Kanisius.

Poespo, Goet. (2000). Teknik Menggambar Mode Busana. Yogyakarta: Penerbit Kanisisius.

Ramayulis, Rita. (2008). Alternatif Untuk Langsing. Jakarta: Penebar Swadaya.

Syafri, Haswita. (2007). Konstruksi Pola Busana Wanita. Padang: Penerbit DIP Universitas Negeri Padang.

Soekarno. (2002). Buku Penuntun Membuat Pola Tingkat Dasar. Jakarta: PT. Gramedia Pustaka Utama.

Sugiyono. (2009). Metode Penelitian Pendidikan Pendekatan Kualitatif, Kuantitatif, Dan $R \& D$. Bandung: Alfabeta.

Sunardi, Yohanes. (2012). Sehat Itu Pilihan. Yogyakarta: Andi. 